\title{
EFEITO DE SISTEMAS DE MANEJO NAS PROPRIEDADES FÍSICAS DE UM LATOSSOLO VERMELHO-ESCURO
}

\author{
EFFECT OF SOIL MANAGEMENT ON SOIL PHYSICAL \\ PROPERTIES OF AN OXISOL
}

\section{Deonir Secco ${ }^{1}$ Clovis Orlando Da Ros ${ }^{2}$ Jackson Ernani Fiorin ${ }^{3}$ Carlito Veck Pautz ${ }^{4}$ Luciano Pasa $^{4}$}

\section{RESUMO}

Este trabalho foi realizado em 1995 na área experimental da Universidade de Cruz Alta, UNICRUZ, Cruz Alta - RS, com o objetivo de avaliar a influência de diferentes sistemas de manejo do solo nas propriedades físicas de um latossolo vermelho-escuro distrófico, bem como no rendimento de grãos da cultura da soja. $O$ delineamento experimental utilizado foi o de blocos ao acaso com quatro repetições. Os sistemas de manejo do solo foram: (1) plantio direto contínuo -PDC; (2) plantio direto e escarificação de acordo com a necessidade (sistema dinâmico) PDSD; (3) plantio direto no verão com escarificação no outono/inverno - PD V; (4) plantio convencional: escarificador mais grade niveladora - PCEG; $e,(S)$ plantio convencional: arado de discos mais grade niveladora-PCAG. Determinou-se o espaço poroso (porosidade total, macro e microporosidade) e a densidade do solo. As amostras foram coletadas em dois pontos por parcela nas profundidades de 0-7, 7-14 e 14-21 cm. A densidade do solo foi maior nas profundidades de $0-7 \mathrm{~cm}$ e 7 $14 \mathrm{~cm}$ para o tratamento PDC que diferiu dos demais tratamentos à exceção ao tratamento PDSD. A porosidade lote $e$ a microporosidade foram menores nos tratamentos PDC e PDSD, nas profundidades de 0-7, 7-14 e 14-21 cm, quando comparados aos tratamentos P D V, PCEG e PCAG. Para a microporosidade, apenas na profundidade de $7-14 \mathrm{~cm}$ encontrou-se diferença significativa entre os valores, onde o tratamento PDC diferiu com valor superior apenas do tratamento PCAG. O rendimento de grãos de soja não diferiu entre os sistemas de manejo do solo utilizados.
Palavras-chave: espaço poroso, densidade, plantio direto.

\section{SUMMARY}

This research v/as carried out in 1995 in the experimental area of the University of Cruz Alta, UNICRUZ, Cruz Alta, RS, aiming to evaluate the effects of different soil management systems on soil physical properties of an oxisol, as well as on soybean yield. The experimental design was a completely randomized blocks with four replications. Soil management systems used were; (1) continuously no-tillage - T1; (2) no-tillage and escarification as needed (dynamic system) - T2; (3) summer no-tillage with Autumn/Winter escarification - T3; (4) conventional tillage: escarification plus harrow disking - T4; and, (5) conventional tillage: disk plowing plus harrow disking - T5. Porous space (total porosity, macro and micro porosity) and bulk density were determined. Samples were collected in two sites in each experimental unit and at depths 0/0-7, 7-14 and 14-21cm. Soil density was higher at the depths ofO-7 and 7-14 cm for the CNT treatment, which was different from the other treatments, except from the NTDS treatment. Total porosity and macro porosity were smaller in the 77 and $T 2$ treatments at the depths 0/0-7, 7-14 and 14-21 cm, as compared with the T3, T4 and T5 treatments. In relation to the micro porosity, significant difference among the values was only found at the depth of 7-14 cm, where the TI treatment differed with a higher value only from the T5 treatment. Soybean grain yield did not show any difference among the soil management systems used.

\footnotetext{
${ }^{1}$ Professor do Curso de Agronomia, UNICRUZ, Caixa Postal 858, 98025-810, Cruz Alta - RS. Autor para correspondência.

${ }^{2}$ Professor do Curso de Agronomia, UNICRUZ.

${ }^{3}$ Engenheiro Agrônomo, Mestre Pesquisador FUNDACEP FECOTRIGO.

${ }^{4}$ Aluno do curso de Agronomia - UNICRUZ.
} 
Key words: porous space, bulk density, no-tillage.

\section{INTRODUÇÃO}

No Rio Grande do Sul, grande parte das lavouras conduzida no sistema de plantio direta, está na região do planalto e em sua maioria sobre latossolos. O plantio direto parece ser o sistema que pode proporcionar a auto-sustentabilidade das produções agropecuárias. Porém, neste sistema, tem surgido problema de compactação subsuperficial devido a características texturais de alguns latossolos, pelo tráfego de máquinas para implantação das culturas, tratos culturais e colheita.

Em sistema de plantio direto o solo é submetido a menor tráfego, porém, não é revolvido no processo agrícola (VIEIRA, 1981). Em função disso, há uma tendência a compactação subsuperficial do solo. A compactação tem sido verificada através do aumento da densidade do solo e da microporosidade, da diminuição da porosidade total e, principalmente, da microporosidade (SIDIRAS $\boldsymbol{e t} \boldsymbol{a l} .$, 1984), sendo estas variações mais freqüentes em solos de textura argilosa (RAGHAVAN et al., 1977).

TORRES \& SARAIVA (1995), conduziram trabalho comparando o efeito de quatro sistemas de preparo, em latossolo roxo distrófico, textura argilosa, nas profundidades de 0-8; 8-16 e $16-24 \mathrm{~cm}$, onde os tratamentos plantio direto e o preparo com grade pesada apresentaram maiores valores de densidade e menores de microporosidade na profundidade de $8-16 \mathrm{~cm}$, quando comparado aos tratamentos preparo convencional e preparo com escarificador.

A avaliação destes parâmetros físicos em áreas sob plantio direto em latossolos na região de Cruz Alta-RS, ainda não foi devidamente quantificados, embora se acredita que este sistema melhore sobremaneira a reestruturação do solo. Assim, verifica-se a necessidade de realizar pesquisas que avaliem o efeito ocasionado ao solo pelo sistema de plantio direto, visando a quantificação da influência dos parâmetros físicos na reestruturação do solo, através do monitoramento das condições físicas antes e após a implantação do mesmo.

Este trabalho objetivou avaliar a influência de diferentes sistemas de manejo nas propriedades físicas de um latossolo vermelhoescuro, bem como no rendimento de grãos da cultura da soja.

\section{MATERIAIS E MÉTODOS}

O experimento foi conduzido de 1994 a 1995 na área experimental da Universidade de Cruz
Alta, em Convênio entre o Curso de Agronomia e FUNDACEP FECOTRIGO. O solo é classificado como latossolo vermelho-escuro distrófico, textura argilosa, substrato basalto e relevo ondulado (BRASIL, 1973). Antes da instalação do experimento, a área vinha sendo cultivada a dois anos sob o sistema de plantio direto com as cultura de soja e feijão no verão e aveia no inverno. Alguns parâmetros físicos do solo, para caracterizar a área experimental, encontram-se na Tabela 1 .

Tabela 1 - Parâmetros físicos da área experimental antes da instalação do experimento. Cruz Alta, RS. 1995.

\begin{tabular}{lcccc}
\hline & \multicolumn{4}{c}{ Profundidade $(\mathrm{cm})$} \\
\cline { 2 - 5 } Parâmetros Físicos & $0-7$ & $7-14$ & $14-21$ & $0-20$ \\
& & & & \\
& & & & \\
& & & & \\
& & & & \\
Densidade do solo $\left(\mathrm{g} \mathrm{cm}^{-3}\right)$ & 0,570 & 0,512 & 0,504 & $*$ \\
Porosidade total $\left(\mathrm{dm}^{-3} \mathrm{dm}^{-3}\right)$ & 0,283 & 0,197 & 0,182 & $*$ \\
Macroporosidade $\left(\mathrm{dm}^{-3} \mathrm{dm}^{-3}\right)$ & 0,287 & 0,315 & 0,322 & $*$ \\
Microporosidade $\left(\mathrm{dm}^{-3} \mathrm{dm}^{-3}\right)$ & $*$ & $*$ & $*$ & 477 \\
Argila $\left(\mathrm{g} \mathrm{kg}^{-1}\right)$ & $*$ & $*$ & $*$ & 173 \\
Areia total $\left(\mathrm{g} \mathrm{kg}^{-1}\right)$ & $*$ & $*$ & $*$ & 2,62 \\
Silte $\left(\mathrm{g} \mathrm{kg}^{-1}\right)$ & & & & $*$ \\
Densidade partícula $\left(\mathrm{g} \mathrm{cm}^{-3}\right)$ & & & & $*$ \\
\hline
\end{tabular}

O delineamento experimental utilizado foi em blocos ao acaso com quatro repetições. Cada unidade experimental mediu 10 x 30 metros. Os tratamentos que caracterizaram os sistemas de manejo do solo foram: (1) plantio direto contínuo (PDC); (2) plantio direto e escarificação de acordo com a necessidade (sistema dinâmico) (PDSD); (3) plantio direto no verão com escarificação no outono/inverno (PDV); (4) plantio convencional: escarificador mais grade niveladora (PCEG) e; (5) plantio convencional: arado de disco mais grade niveladora (PCAG). O tratamento PDSD não recebeu escarificação no primeiro ano.

Em agosto de 1995, após a colheita da cultura da soja, ou seja, após aplicação dos tratamentos na cultura de inverno e verão, foi avaliada a densidade do solo, retirando-se duas subamostras por parcela através de anéis volumétricos de $3,0 \mathrm{~cm}$ de altura e $8,5 \mathrm{~cm}$ de diâmetro, nas profundidades de0-7 ;7-14el4-21 cm.

O espaço poroso do solo (porosidade total, macro e microporosidade), foi determinado após a colheita da cultura de verão e nas mesmas profundidades. Para a microporosidade foram coletadas amostras indeformadas de solo e no laboratório estas 
amostras foram parafinadas e saturadas com água, sendo considerada como microporosidade, o conteúdo volumétrico de água equilibrada na mesa de tensão a $60 \mathrm{~cm}$ de coluna de água. A porosidade total foi calculada através da equação- PT $=1$ $\mathrm{Ds} / \mathrm{Dp}$, onde PT $=$ Porosidade total, $\mathrm{em} \mathrm{dm}^{3} \mathrm{dm}^{-3}$; Ds $=$ Densidade do solo, em $\mathrm{g} \mathrm{cm}^{-3} ; \mathrm{Dp}=$ Densidade de partícula, em $\mathrm{g} \mathrm{cm}^{-3}$ e, a macroporosidade foi calculada por diferença entre a porosidade total e a microporosidade.

$\mathrm{O}$ rendimento de grãos de soja foi avaliado tomando-se aleatoriamente, duas subamostras por parcela, de quatro fileiras com cinco metros de comprimento, totalizando uma área oito metros quadrados. A análise estatística dos resultados foi realizada através da análise da variância e as médias de tratamentos comparadas pelo teste de Duncan em nível de $5 \%$ de significância, para cada profundidade e para o rendimento de grãos.

\section{RESULTADOS E DISCUSSÃO}

A densidade do solo foi maior nas profundidades de $0-7 \mathrm{~cm}$ e 7 $14 \mathrm{~cm}$ para o tratamento PDC que diferiu dos demais tratamentos à exceção ao tratamento PDSD para a profundidade de $0-7 \mathrm{~cm}$. Já na profundidade de 14-21 cm, diferiu apenas do tratamento PCAG (Tabela 2). Isso não significa, necessariamente, que ocorreu incremento no PDC e PDSD, mas demonstra uma redução naqueles que foram mobilizados (PDV, PCEG e PCAG). Estes resultados são semelhantes aos de VIEIRA \& MUZILLI (1984), que ao conduzirem um ensaio em latossolo vermelhoescuro, textura argilosa, comparando o sistema de preparo convencional e o plantio direto sob três rotações de cultura, verificaram ao final do quarto ano de cultivo de verão, aumento significativo no plantio direto na densidade do solo e microporosidade, com conseqüente redução da porosidade total e microporosidade, na camada superficial do solo. Já ALBUQUERQUE et al.,(1995) ao avaliarem os sistemas de manejo plantio direto e convencional com rotações de culturas após sete anos contínuos, em latossolo vermelhoescuro distrófico, não encontraram diferença significativa na densidade, porosidade total, macro e microporosidade.

Os tratamentos que não foram mobilizados (PDC e PDSD), mostraram comportamento semelhante entre si, com valores inferiores para a porosidade total e macroporosidade, nas três profundidades avaliadas, quando comparados aos tratamentos que foram mobilizados (PDV, PCEG e PCAG) (Tabela 2). Isto demonstra que os tratamentos que sofreram mobilização, tiveram incrementos para a porosidade total e macroporosidade quando comparado aos valores dos tratamentos sem mobilização. KLEPKER \& ANGHINONI (1995), ao analisarem as características

Tabela 2 - Densidade do solo $\left(\mathrm{g} \mathrm{cm}^{-3}\right)$, porosidade total, macro e microporosidade $\left(\mathrm{dm}^{-3} \mathrm{dm}^{-3}\right)$ de um latossolo vermelho-escuro sob diferentes sistemas de manejo e coeficiente de variação (CV), Cruz Alta, RS. 1995.

\begin{tabular}{|c|c|c|c|c|}
\hline $\begin{array}{l}\text { Sistema de } \\
\text { Manejo do } \\
\text { solo }^{1}\end{array}$ & $\begin{array}{l}\text { Densidade } \\
\text { do solo }\end{array}$ & $\begin{array}{l}\text { Porosidade } \\
\text { total }\end{array}$ & Macroporosidade & Microporosidade \\
\hline & \multicolumn{4}{|c|}{ Profundidade $0-7 \mathrm{~cm}$} \\
\hline PDC & $1,24 \mathrm{a}^{2}$ & $0,53 b$ & $0,20 b$ & 0,32 \\
\hline PDSD & $1,14 \mathrm{ab}$ & $0,56 a b$ & $0,25 \mathrm{ab}$ & 0,31 \\
\hline PDV & $1,08 \mathrm{~b}$ & $0,59 \mathrm{a}$ & $0,30 \mathrm{a}$ & 0,29 \\
\hline PCEG & $1,09 b$ & $0,58 \mathrm{a}$ & $0,31 \mathrm{a}$ & 0,28 \\
\hline PCAG & $1,12 b$ & $0,57 \mathrm{~b}$ & $0,29 \mathrm{a}$ & 0,28 \\
\hline \multirow[t]{2}{*}{$\mathrm{C} \mathrm{V}(\%)$} & $6,08 *$ & $4,64 *$ & $17,40 *$ & $8,32^{\text {ns }}$ \\
\hline & \multicolumn{4}{|c|}{ Profundidade $7-14 \mathrm{~cm}$} \\
\hline PDC & $1,31 \mathrm{a}$ & $0,50 \mathrm{~b}$ & $0,16 b c$ & $0,34 \mathrm{ab}$ \\
\hline PDSD & $1,32 \mathrm{a}$ & $0,49 b$ & $0,15 \mathrm{c}$ & $0,35 \mathrm{a}$ \\
\hline PDV & $1,19 b$ & $0,54 \mathrm{a}$ & $0,24 \mathrm{a}$ & $0,31 b c$ \\
\hline PCEG & $1,23 b$ & $0,59 \mathrm{a}$ & $0,21 \mathrm{ab}$ & $0,32 \mathrm{abc}$ \\
\hline PCAG & $1,18 b$ & $0,55 \mathrm{a}$ & $0,26 \mathrm{a}$ & $0,29 \mathrm{c}$ \\
\hline \multirow[t]{2}{*}{$\mathrm{C} \mathrm{V}(\%)$} & $3,71 *$ & $3,39 *$ & $17,51^{*}$ & $6,17 *$ \\
\hline & \multicolumn{4}{|c|}{ Profundidade $14-21 \mathrm{~cm}$} \\
\hline PDC & $1,29 \mathrm{ab}$ & $0,51 b c$ & $0,16 b c$ & 0,34 \\
\hline PDSD & $1,32 \mathrm{a}$ & $0,49 \mathrm{c}$ & $0,15 \mathrm{c}$ & 0,35 \\
\hline PDV & $1,19 b c$ & $0,54 \mathrm{ab}$ & $0,24 \mathrm{ab}$ & 0,30 \\
\hline PCEG & $1,18 b c$ & $0,55 \mathrm{ab}$ & $0,23 \mathrm{ab}$ & 0,31 \\
\hline PCAG & $1,17 \mathrm{c}$ & $0,55 \mathrm{a}$ & $0,26 \mathrm{a}$ & 0,30 \\
\hline C V $(\%)$ & $5,60 *$ & $4,96^{*}$ & $24,96 *$ & $8,59^{\mathrm{ns}}$ \\
\hline
\end{tabular}

${ }^{1}$ PDC: plantio direto contínuo; PDSD: plantio direto e escarificação de acordo com a necessidade (sistema dinâmico); PDV: plantio direto no verão com escarificação no outono/inverno; PCEG: plantio convencional: escarificador mais grade niveladora; PCAG: plantio convencional: arado de discos mais grade niveladora. ${ }^{2}$ Médias com letras distintas na coluna e pro profundidade diferem pelo teste de Duncan a $5 \%$ de probabilidade. ${ }^{\mathrm{ns}}$ diferença entre os tratamentos não significativa pelo teste de F. *diferença entre os tratamentos significativos a $5 \%$ de erro pelo teste de $\mathrm{F}$. 
físicas de um podzólico vermelho-escuro afetadas pêlos métodos de preparo convencional, em faixas e plantio direto, nas profundidades de $05-10 \mathrm{~cm}$ e $20-$ $25 \mathrm{~cm}$, concluíram que na profundidade de $20-25 \mathrm{~cm}$, em comparação com a de $05-10 \mathrm{~cm}$, em todos os métodos de preparo do solo, que a macroporosidade e a porosidade total foram menores, o que evidenciou um adensamento na camada superficial do solo.

Para a microporosidade, apenas na profundidade de $7-14 \mathrm{~cm}$ encontrou-se diferença significativa entre os valores, onde o tratamento PDC diferiu com valor superior apenas do tratamento PCAG (Tabela 2). Estes valores concordam, em parte, com os encontrados por CASSOL \& ANGHINONI (1995), que ao avaliarem as características físicas de um podzólico vermelhoescuro após quatro anos de cultivo nos sistemas de plantio direto e convencional, nas profundidades de $0-2,5 ; 2,5-7,5$ e $7,5-15 \mathrm{~cm}$, verificaram que para a microporosidade não houve efeito nem para preparo nem para profundidade e os valores oscilaram em torno de $30 \%$ nas profundidades avaliadas.

$\mathrm{O}$ rendimento médio de grãos de soja foi de $3.099 \mathrm{~kg} / \mathrm{ha}$, com valores de $2.962 \mathrm{~kg} / \mathrm{ha}$ no PDV a $3265 \mathrm{~kg} / \mathrm{ha}$ no PCAG, porém esta diferença não foi significativa, com coeficiente de variação $(\mathrm{CV})$ em $6,32 \%$. Estes resultados diferem com os encontrados por RUEDELL (1995) que, ao avaliar o rendimento médio de grãos de soja em resposta aos manejos de solo plantio direto e convencional, em latossolo vermelho-escuro distrófico após nove anos de avaliação, concluiu que a cultura da soja produziu mais no plantio direto em relação ao convencional, atingindo uma diferença de $12,4 \%$ no período avaliado.

\section{CONCLUSÕES}

A densidade do solo é maior nas profundidades de $0-7 \mathrm{~cm}$ e $7-14 \mathrm{~cm}$ para o plantio direto continuo que difere dos demais tratamentos à exceção ao plantio direto e escarificação de acordo com a necessidade (sistema dinâmico). A porosidade total e a macroporosidade são menores nos tratamentos plantio direto contínuo e no plantio direto e escarificação de acordo com a necessidade (sistema dinâmico), nas profundidades de 0-7, 7-14 e 14-21 cm, quando comparado aos tratamentos plantio direto contínuo, plantio convencional: escarificador mais grade niveladora e plantio convencional: arado de discos mais grade niveladora. Para a microporosidade, apenas na profundidade de $7-14 \mathrm{~cm}$ encontrou-se diferença significativa entre os valores, onde o plantio direto contínuo difere com valor superior apenas do tratamento plantio convencional: arado de discos mais grade niveladora; e, No primeiro ano de avaliação não ocorre influência dos sistemas de manejo do solo sobre o rendimento de grãos de soja.

\section{REFERÊNCIAS BIBLIOGRÁFICAS}

ALBUQUERQUE, J.A., REINERT, D.J., FIORIN, S.E., $\boldsymbol{e}$ t al Rotação de culturas e sistemas de manejo do solo: Efeito sobre a forma da estrutura do solo ao final de sete anos. $\mathbf{R}$ Bras Ci Solo, Campinas, v. 19, p. 115-119. 1995.

BRASIL. Ministério da Agricultura. Departamento Nacional de Pesquisa Agropecuária. Divisão de Pesquisas Pedologias. Levantamento de Reconhecimento dos Solos do Estado do Rio Grande do Sul. Recife. 1973. 431 p. (Boletim Técnico, 30).

CASSOL, D., ANGHINONI, I. Alterações nas Características de um Podzólico Vermelho-Escuro Após Quatro Anos de Cultivo nos Sistemas de Plantio Direto e Convencional. In: CONGRESSO BRASILEIRO DE CIÊNCIA DO SOLO, 25, 1995, Viçosa, MG. Anais... Viçosa, SBCS, UFV, 1995. 2429 p. p. 1843-44.

KLEPK£R, D., ANGHINONI, I. Características Físicas e Químicas do Solo Afetadas por Métodos de Preparo e Modos de Adubação. In: CONGRESSO BRASILEIRO DE CIÊNCIA DO SOLO, 25,1995, Viçosa, MG. Anais... Viçosa, SBCS, UFV, 1995. 2429 p. p. 1854-56.

RACHAVAM, G.S.V., MCKYES, E., CHASSÊ, M. Effete of well slip on soil compaction. J of Agric Eng Rés, St. Joseph, v. 22, p.79-83, 1977.

RUEDELL, J. Plantio Direto na Região de Cruz Alta. Convénio FUNDACEP/BASF. FUNDACEP FECOTRIGO, Cruz Alta, RS,1995.134 p.

TORRES, E., SARAIVA, O.F. Doze Anos de Manejo do Solo em Soja. In: CONGRESSO BRASILEIRO DE CIÊNCIA DO SOLO, 25, 1995, Viçosa, MG. Anais... Viçosa, SBCS, UFV, 1995. 2429 p. p. $1802-03$.

SIDIRAS, N., VIEIRA, S.R., ROTH, C.H. Determinação de algumas características físicas de um latossolo roxo distrófico sob plantio direto e preparo convencional. R Bras Ci Solo, Campinas, v.8,p.265-268, 1984.

VIEIRA, M,J. Propriedades físicas do solo. In: Plantio direto no Estado do Paraná. Londrina, 981. p. 19-32. (IAPAR. Circular, 23).

VIEIRA, M.J., MUZILLI, O. Características físicas de um latossolo vermelho-escuro sob diferentes sistemas de manejo. Pesq Agropec Brás, Brasília, v. 19, n. 7, p. 873-882, 1984. 